\title{
The Clintons go to Washington: a healthy move?
}

\section{Americans expect some reforms}

Like the overnight success of a movie star, health care reform in the United States has leapt from oblivion to notoriety. In the autumn of 1991 the Bush administration showed no interest in health care reform. Then Harris Wofford upset a popular Republican senator in Pennsylvania, a victory largely due to Wofford's campaign slogan, "Universal access to health care." This victory ignited a political fire, which in turn fuelled voter concerns and inflamed the key participants into action. Bill Clinton's election was, of course, primarily the result of a troubled American economy. From January 1992 to the voting hour on 3 November, however, health care was consistently the voters' second greatest concern. Now the new president has appointed his wife, Hillary Rodham Clinton, to lead a task force on health care reform. What should she do?

The Clintons must address the driving forces behind the upward spiralling costs of health care if America is to truly reform its health care system. Access to health care insurance is driven by the cost of coverage, which in turn is driven by the cost of care. These driving forces are directly related to the supply driven nature of health care. They include the high intensity services delivered to insured patients-especially, but not exclusively, patients aged over 65 . For example, with scant evidence that either length or quality of life is enhanced by coronary artery bypass surgery, American surgeons are four times more likely than Canadian surgeons to perform this procedure on patients aged over $75 .{ }^{12}$ Although the popularity of living wills and "right to die" initiatives is growing, these will do little to address the overuse of procedures and services that fuels the United States health care system.

Much tighter controls are needed over the use of technologies and procedures if health care costs are to be controlled. These controls could be put in place through legislation or indirectly through the expansion of tightly managed care plans that in turn monitor use of technology. If legislative controls are used then developing sophisticated clinical practice guidelines for only those procedures with high cost and high variability, and requiring those guidelines to apply to all providers and payers, would be a healthy start. A global budget, or even a more flexible expenditure target, could begin to slow total system costs.

The managed competition approach-creating health insurance purchasing corporations which help small businesses and individuals choose between competing health plans based on cost and quality-is an untested theory. If it works appropriate use of technologies and procedures will lead to success for any health plan. If it doesn't low income workers will be stuck in low option plans, high income workers will opt out to fee for service schemes, and "quality" health care will be as elusive as it is now.

A related driving force is the ratio of specialist to general physicians, which the United States arguably has backwards - two specialists for every generalist. Specialists are far more likely to recommend or provide technologically intense services. The fresh supply of specialists pouring out each year can be altered only by restructuring American medical education, but the intensity of services provided by existing specialists could be altered by any of the strategies described-practice guidelines, global budgets, or managed competition.

Not only is the total cost of the health care system overwhelming (14\% of gross domestic product, $\$ 800 \mathrm{bn}$ a year), this cost is unevenly distributed. It favours the employed with good incomes on the one hand and the
Medicare and Medicaid programmes on the other. Risk selection by large insurers and cost shifting by federal and state agencies leave lower and middle income families paying a larger share of the bill. They also leave them more vulnerable to losing their insurance. Taxing all health insurance benefits provided by employers over a basic insurance package would reduce some inequities at the high end while producing revenues to help small employers and self employed workers to buy insurance. Requiring all insurers to provide a single premium rate within a community and to guarantee to issue and renew policies to any member of that community (eliminating the practice of "red lining," refusing to cover people with certain illnesses or risk factors) would reduce many inequities as well as overall costs. So too would establishing the same charges for both public and private payers. These solutions could be put in place with or without the implementation of a managed competition system.

What is most likely to happen? The relation between the economy and health care reform is vital. The vulnerable middle class-worried about losing jobs and health insurance and not being able to afford health care-was the force behind the Clintons' election. Unless the needs of this group are addressed it will be the force behind their defeat in 1996 .

To win again in 1996 the Clintons must address the country's economic woes first. If Americans believe that progress is underway in creating jobs and reducing the deficit they will be satisfied with incremental health care reform. Consistent with campaign promises, insurers and pharmaceutical companies are certain targets, but providers will not be let off scot free. The most likely incremental reforms include insurance premium caps and price controls on hospitals, doctors, and pharmaceuticals. Beyond price controls, employer sponsored health care benefits over a basic insurance package are likely to be taxed. These revenues will probably be used to increase middle class access to health care by providing tax credits to small businesses in a managed competition "play or pay" system.

A less expensive, but less politically viable solution would be to expand children's access first, through a new programme or by expanding Medicaid. Given the leading role that Ms Rodham Clinton and Donna Shalala, the Health and Human Services secretary, appear to be taking in developing solutions, and their explicit interest in children, we should watch for this "wild card."

Associate Director,

ELLEN M MORRISON

Health Care Programme,

Institute for the Future,

Menlo Park, CA 94025-7020, USA 1 Rublec DA. Medical technology in Canada, Germany, and the United States. Health Affairs
1989;Fall:178-81.
2 McPherson K. International differences in medical care practices. Health Care Financing Review
1991; (Annual Supplement):9-20.

\section{Correction}

\section{Driving and diabetes}

The three words "by the patient" were omitted from the end of the fifth paragraph of this editorial by Brian M Frier (21 November, $p$ 1238-9). The final sentence of the paragraph should have read: "The assessment of vision of non-insulin dependent diabetic drivers should therefore not be neglected, and worsening vision from cataracts or retinopathy should be reported to the licensing agency by the patient." 